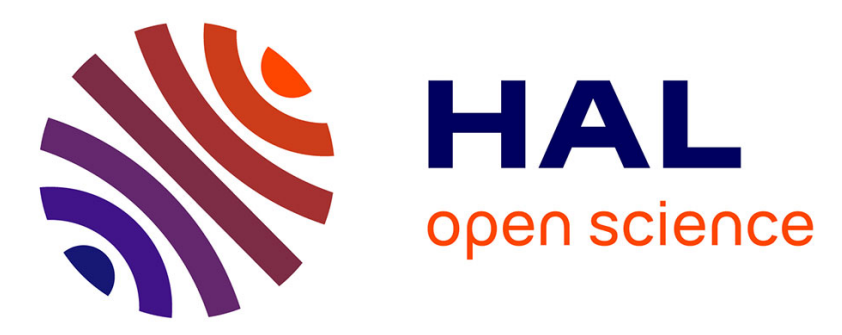

\title{
Attention-deficit/hyperactivity disorder in the offspring following prenatal maternal bereavement: a nationwide follow-up study in Denmark
}

\author{
Jiong Li, Jørn Olsen, Mogens Vestergaard, Carsten Obel
}

\section{- To cite this version:}

Jiong Li, Jørn Olsen, Mogens Vestergaard, Carsten Obel. Attention-deficit/hyperactivity disorder in the offspring following prenatal maternal bereavement: a nationwide follow-up study in Denmark. European Child and Adolescent Psychiatry, 2010, 19 (10), pp.747-753. 10.1007/s00787-010-0113-9 . hal-00594912

\section{HAL Id: hal-00594912 \\ https://hal.science/hal-00594912}

Submitted on 22 May 2011

HAL is a multi-disciplinary open access archive for the deposit and dissemination of scientific research documents, whether they are published or not. The documents may come from teaching and research institutions in France or abroad, or from public or private research centers.
L'archive ouverte pluridisciplinaire HAL, est destinée au dépôt et à la diffusion de documents scientifiques de niveau recherche, publiés ou non, émanant des établissements d'enseignement et de recherche français ou étrangers, des laboratoires publics ou privés. 
Attention-deficit /hyperactivity Disorder (ADHD) in the offspring following prenatal maternal bereavement: a nationwide follow-up study in Denmark

Jiong $\mathrm{Li}^{1}$, MD, PhD, Jørn Olsen ${ }^{1,2,}$ Mogens Vestergaard ${ }^{3}, \mathrm{MD}, \mathrm{PhD}$, Carsten Obel ${ }^{3}$, $\mathrm{MD}, \mathrm{PhD}$

1. Danish Epidemiology Science Centre, Department of Epidemiology, Institute of Public Health, University of Aarhus, Denmark

2. Department of Epidemiology, School of Public Health, University of California, Los Angeles, USA

3. Department of General Practice, Institute of Public Health, University of Aarhus, Denmark

\section{Correspondence to:}

Jiong Li, MD, PhD

The Danish Epidemiology Science Centre,

Department of Epidemiology, Institute of Public Health,

The University of Aarhus, Denmark.

Phone:+45 8942 6092, Fax: +45 86131580

Email: $11 @$ soci.au.dk

Running head: Prenatal stress and ADHD

Word count: 2367 


\begin{abstract}
Severe prenatal stress exposure has been found to increase the risk of neuropsychiatric conditions like schizophrenia. We examined the risk of Attention-deficit/hyperactivity disorder (ADHD) in the offspring following prenatal maternal bereavement, as a potential source of stress exposure. We conducted a nationwide population-based cohort study including all 1015912 singletons born in Denmark from 1987 to 2001. A total of 29094 children were born to women who lost a close relative during pregnancy or up to one year before pregnancy. These children were included in the exposed cohort and other children were in the unexposed cohort. We used Cox regression to estimate hazard ratios for ADHD, defined as the first-time ADHD hospitalization or first-time ADHD medication after 3 years of age. Boys born to mothers who were bereaved by unexpected death of a child or a spouse, had a 72\% increased risk of ADHD (Hazard ratio $[\mathrm{HR}]=1.72,95 \%$ confidence interval $[\mathrm{CI}]=1.09-2.73$ ). Boys born to mothers who lost a child or a spouse during 0-6 months before pregnancy and during pregnancy had a HR of 1.47 $(95 \% \mathrm{CI}=1.00-2.16)$ and $2.10(95 \% \mathrm{CI}=1.16-3.80)$, respectively. Our findings suggest that prenatal maternal exposure to severe stress may increase the risk of ADHD in the offspring.
\end{abstract}

Key words Attention-deficit/hyperactivity Disorder (ADHD); stress; bereavement; fetal programming; child psychiatry. 
Attention deficit hyperactivity disorder (ADHD) is one of the most common childhood psychiatric disorders $(1 ; 2)$. This disease causes a number of adverse academic and vocational conditions in children, and exerts stress to the affected families and economic burden on society (3). The disorder has a substantial genetic component but epidemiological studies suggest that environmental factors operating in early life most likely contribute to the disease risk (3-5). Evidence from animal studies suggests that maternal stress during pregnancy may affect fetal neurodevelopment $(6 ; 7)$. One of the underlying mechanisms is termed as 'fetal programming', which occurs when the normal pattern of fetal development is disrupted by an abnormal stimulus or insult at critical time points $(6 ; 8)$. Excessive glucocorticoids following stress in pregnant mothers may have such a programming effect on brain development (6-9). In epidemiological studies, prenatal stress has been linked to congenital malformations (10), cerebral palsy (11), and psychiatric disorders including schizophrenia(12;13). Anxiety during pregnancy has been associated with ADHD phenotypical behavior in the offspring $(14 ; 15)$ but no published studies have evaluated the association between prenatal stress and the risk of ADHD.

We hypothesized that prenatal stress had a programming effect on brain development (16-18) and could increase the risk of ADHD in childhood. We examined this hypothesis in a cohort study based on data from several nationwide registers in Denmark. Bereavement is a severe life event known to induce stress $(19 ; 20)$ and death of a child is rated as the most severe type of bereavement $(21 ; 22)$. We thus expected the children born to mothers who lost a child during the prenatal period had a higher risk of ADHD than 
other children. We also anticipated the effect of prenatal stress to be modified by the timing $(10 ; 12 ; 13)$ and other characteristics of bereavement like cause of death $(19 ; 20 ; 23)$. 


\section{Method}

We conducted a nationwide cohort study based on data from 6 Danish national registers, namely, the Civil Registration System (24), the Medical Birth Register (25), the Psychiatric Central Register (26), the Hospital Discharge register (27), Register of Medicinal Product Statistics (28), and the Integrated Database for Longitudinal Labour Market Research (IDA) (29). The national board of Health and the Danish Data Protection Agency approved the project.

\section{Study population, exposure, and follow up}

We used data from the Danish Civil Registration System (24) to identify all singletons born in Denmark between January 1, 1987 and December 31, 2001, and their next of kin (mother, father, siblings, mother's siblings, and mother's parents). All live-born children and new residents in Denmark are assigned a unique civil personal registration number (CPR number), which is stored in the Danish Civil Registration System together with information on vital status, emigration, disappearance, address, and CPR numbers of family members. The CPR number is used as the key to individual information in all national registries.

Among the 1015912 singletons, 29094 children were included in the exposed cohort as they were born to mothers who lost a child, or a spouse, or a sibling, or a parent during the pregnancy or up to one year before the pregnancy. The remaining children (986 816) were included in the unexposed cohort. All children were followed from 3 years of age 
until the first diagnosis of ADHD, first use of ADHD medication, or death, or emigration, or December 31, 2006, whichever came first.

\section{Attention-deficit/hyperactivity Disorder (ADHD)}

A child was defined as an ADHD case if the child, for the first time after her/his third birthday, had a hospital diagnosis of ADHD (ICD 10 code F90), or redeemed ADHD medication. According to the diagnostic criteria, we excluded children with autism (ICD 10 codes F84.0, F84.1) and with mental retardation (ICD 10 codes F70-79). We also examined ADHD hospital diagnoses and ADHD medication as separate outcomes.

Information on ADHD diagnosis (both as inpatients and as outpatients) was obtained from the Danish Psychiatric Central Register (26) and Danish National Hospital Register (27). Diagnostic information is based on the Danish version of the International Classification of Diseases, $10^{\text {th }}$ revision (ICD-10) from 1994 and onwards. From 1995 outpatient contacts are also registered.

Information on ADHD medication was obtained from the Register of Medicinal Product Statistics for 1996-2006 (28). All Danish residents are provided tax-supported health care by the National Health Service, which refunds the costs of most physician-prescribed drugs, including ADHD medication with N06BA04 (central stimulating drug only methylphnidate), or N06BA09 (Noradrenalin reuptake inhibitors, atomoxetine), or N06BA07 (modafinil). 


\section{Other variables}

Perinatal factors were retrieved from the Medical Birth Register (25), which was established in 1968 and has been computerized since 1973. It holds data on characteristics of mothers and newborns, such as gestational age, birth weight, Apgar score at 5 minutes, maternal age, and maternal smoking status during pregnancy. Apgar scores evaluate the clinical state of the newborns during first minutes of life and a total score of 10 indicates that the baby is 'in its best possible condition' (25). Maternal smoking status was available for the period of 1991-2001, which was a categorical variable (yes, no) (25). We defined small for gestational age (SGA) as a birth weight below the $10^{\text {th }}$ percentile for gestational age, sex, and parity, based on the distribution within all newborn singletons in Denmark between 1978 and 2004.

Socio-demographic factors for mothers (residential place, education, income, and cohabitation status) were obtained from the Intergrated Database for Longitudinal Labour Market Research (IDA), which contains longitudinal information on demographic variables and socioeconomic data from 1980 and onwards (29).

Data on maternal psychiatric hospital admission (ICD 8 codes 290-299, ICD 10 codes F00-F99) was retrieved from the Central Psychiatric Register (26).

\section{Statistical analysis}

We used Cox regression model (SAS Proc Phreg procedure, version 9.1) to estimate hazard ratios (HRs) (30). To examine whether the associations varied by nature of the 
bereavement, we first categorized the exposed children into two groups: a) children of mothers who lost a child or a spouse, and b) children of mothers who lost a parent, or a sibling, since we assumed that loss of a child or a spouse was more severe than loss of a parent or a sibling $(21 ; 23)$. We further categorized the cause of death into 2 groups: unexpected death (unexpected causes, ICD8 codes 7950 to 7959, ICD 10 codes R95 to R97, motor vehicle accidents, ICD8 codes 8100-8230, ICD10 codes V01 to V89, suicide, ICD8 codes 950 to 959, ICD10 codes X60 to X84, other accidents and violence, ICD8 codes 800 to 807,825 to 949,960 to 999 , ICD10 codes V90 toV99, W00 to X59, X85 to Y89), and death by other causes. In order to examine whether a potential effect of prenatal stress on ADHD differed across different prenatal periods, the exposure window was divided into 3 periods ( 12 to 7 months before pregnancy, 6 to 0 months before pregnancy, and pregnancy). The pregnancy period was further divided into 3 trimesters (0-12 weeks, 13-24 weeks, >24 weeks).

We adjusted for the following potential confounders: gender (male, female), birth year (1987 to 1994, 1994 to 1997,1998 to 2001), maternal age ( $<27$ years, 27 to 30 years, 31 years and over), maternal residential area (capital city of Copenhagen area, cities with over 100,000 inhabitants, other places), maternal education (0 to 9 years, 10 to 11 years, $12+$ years), maternal income (lowest quartile, $2^{\text {nd }}$ quartile, $3^{\text {rd }}$ quartile, highest quartile in the calendar year), maternal cohabitation status (yes, no), maternal history of psychiatric diseases (yes, no), maternal smoking status at pregnancy (yes, no). Gestational age $(<37$ weeks, >=37 weeks), Apgar score at 5 minutes ( 0 to 7,8 to 9,10$)$, SGA (yes, no) were 
added into the models to examine whether the associations were affected by these potential intermediate variables.

The above analyses were performed for boys and girls separately to examine whether gender interacted significantly with the exposure. We further analyzed data after excluding those with low birth weight $(<2500 \mathrm{~g})$, low gestational age at birth $(<37$ weeks), low Apgar scores at 5 minutes $(<10)$ to examine whether a possible effect of stress was seen for children born without those complications. The analyses were also performed restricting the birth years from 1991 to 2001 when maternal smoking status was available. 


\section{Results}

The baseline characteristics of exposed children and unexposed children are presented in Table 1.

Table 2 shows that a total of 10278 children who either received an ADHD diagnosis (6274) or redeemed ADHD medication (7641) during the follow up. There were 3637 children who received both a diagnosis and medication. There were, as expected, more cases in boys (8477) than in girls (1831).

Table 3 presents the hazard ratios (HRs) for ADHD according to maternal bereavement during the prenatal period by gender, type of deceased relatives, and cause of death. Prenatal maternal bereavement by death of a child or spouse was associated with a $37 \%$ increased risk of $\mathrm{ADHD}(\mathrm{HR}=1.37,95 \% \mathrm{CI}=1.03-1.79)$ in male offspring. Boys born to mothers who lost a child or spouse due to unexpected death had a HR of $1.72(95 \% \mathrm{CI}=$ 1.09-2.73). Exposed girls, however, had a similar risk of ADHD as unexposed girls.

Table 4 shows the HRs when diagnosis and medication were treated as separate outcomes in boys. Similar findings were seen as in Table 3, although the associations were not statistically significant. Data for girls only are sparse and not presented.

Table 5 presents the results according to timing of exposure in boys. Maternal bereavement by loss of a child or spouse during pregnancy had a HR of $2.10(95 \% \mathrm{CI}=$ 1.16-3.80), higher than those $\mathrm{HRs}$ in previous periods $(\mathrm{HR}=1.47,95 \% \mathrm{CI}=1.00-2.16$ for 
6-0 months before pregnancy, and $\mathrm{HR}=0.95,95 \% \mathrm{CI}=0.57-1.61$ for 12 to 7 months before pregnancy). The HRs tended to be the highest when bereavement occurred in third trimester, but the confidence intervals were wide because of limited cases in the exposed group. Data for girls only are sparse and not presented.

We observed similar gender-specific and timing-specific results as described above when ADHD diagnosis and ADHD medication were treated as separate outcomes (data not shown). Similar results were also observed when analyses were restricted in children with birth weight $>2500 \mathrm{~g}$, gestational age $>37$ weeks, or Apgar score at 5 minutes of 10 (data not shown). Similar results were also seen when birth year was restricted to the period of 1991-2001. 


\section{Discussion}

We found that boys born to mothers who lost a child or a spouse during the pregnancy had a higher risk of receiving a hospital diagnosis of ADHD or receiving ADHD medication. No such associations were seen for girls, nor for the bereavement by death of other types of relatives.

As early as in 1978 Huttunen et al. introduced the idea of using the loss of a close relative to test the effect of prenatal stress on fetal brain development (12). Other have shown that maternal anxiety or depression during pregnancy was associated with behavioural/emotional problems in the offspring $(14 ; 15)$. To our knowledge, this is the first population-based study to investigate the association between prenatal stress and the risk of ADHD in childhood. As expected $(19 ; 20 ; 23)$, maternal bereavement by death of a child and death by unexpected causes were associated with higher risks than other types of death. Our data suggest that only the most severe type of prenatal stress may contribute to future risk of ADHD.

Our study has a number of important methodological strengths. First, the study was based on a large population-based cohort of all singletons born in Denmark with up to 17 years follow up with minimal loss (24). Thus the study is not biased by selection of study participants or loss to follow up. Second, studies on stress are often limited by too small exposure contrast between the compared groups, or recall bias, which rendered difficulties in interpretation and comparison between studies (31-34). Our data on bereavement from the Danish Civil Registration System are valid and complete (close to 
$100 \%$ ), thus yielding accurate information exposure (24). Third, in contrast to previous studies we were able to adjust for birth outcomes and several maternal factors (smoking status during pregnancy, socio-demographic factors, history of psychiatric illnesses), which were potential confounders (3-5).

A limitation of the study is that not all children with ADHD received a hospital diagnosis in the register system. The majority of children with ADHD are treated as outpatients, which we were able to register but others are treated by child psychiatrists working outside the hospital system and thus not included in registers. By using the prescription data we were able to include most of ADHD cases who were not hospitalized. The primary medication of ADHD is methylphenidate, which only has one other rare indication (narcolepsy). The outcome has therefore a high specificity but a low sensitivity. However, such a low sensitivity is non-differential and will not bias relative estimates of the association.

It has been suggested that the effect of prenatal stress on neurodevelopment may vary by the timing of exposure. Studies on schizophrenia (13) indicated that the first trimester was the most vulnerable period, but studies on other endpoints suggested that the time window of susceptibility was in late pregnancy $(12 ; 35)$. Our findings suggest that exposure to severe stress during late pregnancy may have a greater influence on fetal brain development. ADHD is a less severe and pervasive disorder than schizophrenia and it is expected that later exposure in pregnancy may be more important in relation to ADHD in view of the more matured brain in late pregnancy. 
ADHD is found more often in boys than in girls and evidence from animal studies suggest that the sensitivity to neuro-toxic exposures may depend on gender (36). Furthermore, it has been indicated that the central dopamine system matures slower in males than in females, thus increasing the period of vulnerability in the dopamine transmitter system (37). Our findings in male offspring may be a chance finding due to the fact that we did not have enough cases in girls. ADHD behaviors, as currently defined, are more likely to be identified in boys than girls. The effects of bereavement may also hold for girls, but girls are less often identified by teachers and parents as exhibiting ADHD symptoms-even though they may have the inattentive characteristics (38). Alternatively, bereavement may result in different emotional problems in girls, which needs to be examined in future studies.

In conclusion, the most severe types of prenatal stress during pregnancy may play a role in the development of ADHD in the offspring.

\section{Acknowledgements}

The study was supported by the Danish Medical Research Council (project no. 271-050616, project no. 271-07-0437), Gigtforeningen (R54-A596-B286), Nordic Cancer Union (2008), and NordForsk (070331).

Disclosure: The authors report no conflicts of interest. 


\section{ReferencesReference List}

1. Polanczyk G, de Lima MS, Horta BL, Biederman J, Rohde LA (2007) The Worldwide Prevalence of ADHD: A Systematic Review and Metaregression Analysis. Am J Psychiatry 164:942-948

2. Brown RT, Freeman WS, Perrin JM, Stein MT, Amler RW, Feldman HM, Pierce K, Wolraich ML (2001) Prevalence and Assessment of AttentionDeficit/Hyperactivity Disorder in Primary Care Settings. Pediatrics 107:e43

3. Biederman J (2005) Attention-Deficit/Hyperactivity Disorder: A Selective Overview. Biol Psychiatry 57:1215-1220

4. Banerjee TD, Middleton F, Faraone SV (2007) Environmental risk factors for attention-deficit hyperactivity disorder. Acta Paediatr 96:1269-1274

5. Faraone SV, Doyle AE (2001) The nature and heritability of attentiondeficit/hyperactivity disorder. Child Adolesc Psychiatr Clin N Am 10:299-316

6. Viltart O, Vanbesien-Mailliot CC (2007) Impact of prenatal stress on neuroendocrine programming. ScientificWorldJournal 7:1493-1537

7. Talge NM, Neal C, Glover V (2007) Antenatal maternal stress and long-term effects on child neurodevelopment: how and why? J Child Psychol Psychiatry 48:245-261

8. Welberg LA, Seckl JR (2001) Prenatal stress, glucocorticoids and the programming of the brain. J Neuroendocrinol 13:113-128

9. Gitau R, Cameron A, Fisk NM, Glover V (1998) Fetal exposure to maternal cortisol. Lancet 352:707-708

10. Hansen D, Lou HC, Olsen J (2000) Serious life events and congenital malformations: a national study with complete follow-up. Lancet 356:875-880

11. Li J, Vestergaard M, Obel C, Precht DH, Christensen J, Lu M, Olsen J (2009) Prenatal stress and cerebral palsy: a nationwide cohort study in Denmark. Psychosom Med 71:615-618

12. Huttunen MO, Niskanen P (1978) Prenatal loss of father and psychiatric disorders. Archives of General Psychiatry 35:429-431

13. Khashan AS, Abel KM, McNamee R, Pedersen MG, Webb RT, Baker PN, Kenny LC, Mortensen PB (2008) Higher Risk of Offspring Schizophrenia Following Antenatal Maternal Exposure to Severe Adverse Life Events. Archives of General Psychiatry 65:146-152 
14. O'Connor TG, Heron J, Golding J, Beveridge M, Glover V (2002) Maternal antenatal anxiety and children's behavioural/emotional problems at 4 years: Report from the Avon Longitudinal Study of Parents and Children. The British Journal of Psychiatry 180:502-508

15. O'Connor TG, Heron J, Glover V, the ALSPAC Study Team (2002) Antenatal Anxiety Predicts Child Behavioral/Emotional Problems Independently of Postnatal Depression. [Article]. J Am Acad Child Adoles Psychiatry 41:1470-1477

16. Seckl J (2004) Prenatal glucocorticoids and long-term programming. Euro J Endocrinol 151:U49-U62

17. Weinstock M (2001) Alterations induced by gestational stress in brain morphology and behaviour of the offspring. Prog Neurobiol 65:427-451

18. Weinstock M (2005) The potential influence of maternal stress hormones on development and mental health of the offspring. Brain Behav Immun 19:296-308

19. Osterweis M, Solomon F, Green M (1984) Bereavement: Reactions, Consequences, and Care. National Academy Press, Washington DC

20. Rubin SS, Malkinson R (2001) Parental responses to child loss across the life cycle: clinical and research perspectives. In: Stroebe MS, Hansson RO, Stroebe W (eds) Handbook of Bereavement Research: Consequences, Coping, and Care. American Psychological Association, Washington DC, pp 219-239

21. Skodol AE, Shrout PE (1989) Use of DSM-III axis IV in clinical practice: rating etiologically significant stressors. Am J Psychiatry 146:61-66

22. Levav I, Krasnoff L, Dohrenwend BS (1981) Israeli PERI life event scale: ratings of events by a community sample. Isr J Med Sci 17:176-183

23. Li J, Precht DH, Mortensen PB, Olsen J (2003) Mortality in parents after death of a child in Denmark: a nationwide follow-up study. Lancet 361:363-367

24. Pedersen CB, Gotzsche H, Moller JO, Mortensen PB (2006) The Danish Civil Registration System. A cohort of eight million persons. Dan Med Bull 53:441-449

25. Knudsen LB, Olsen J (1998) The Danish Medical Birth Registry. Dan Med Bull 45:320-323

26. Munk-Jorgensen P, Mortensen PB (1997) The Danish Psychiatric Central Register. Dan Med Bull 44:82-84

27. Andersen TF, Madsen M, Jorgensen J, Mellemkjoer L, Olsen JH (1999) The Danish National Hospital Register. A valuable source of data for modern health sciences. Dan Med Bull 46:263-268 
28. The Danish Medicines Agency. Register of Medicinal Product Statistics. http://www.dkma.dk/1024/visUKLSArtikel.asp?artikelID=10895 . 8-6-2009.

Ref Type: Electronic Citation

29. Denmark Statistics (1991) IDA-an intergrated database for labor market research. (In Danish).(http://www.dst.dk/) (under IDA (Intergrated Database for Arbejdsmarkedsforskning)).

30. SAS Institute (1997) SAS/STAT Software: Changes and Enhancements, Release 6.12. SAS Institute, Cary, NC

31. Avison WR, Gotlib IH (1994) Stress and mental health : contemporary issues and prospects for the future. Plenum, New York

32. Brown GW, Harris TO (1989) Life events and illness . Guilford Press, New York

33. Elliott GR, Eisdorfer C (1982) stress and human health. Springer, New York

34. Miller TW (1996) Theory and assessment of stressful life events. International Universities Press, Madison, Connecticut

35. Schneider ML, Roughton EC, Koehler AJ, Lubach GR (1999) Growth and Development Following Prenatal Stress Exposure in Primates: An Examination of Ontogenetic Vulnerability. Child Dev 70:263-274

36. Weinstock M (2007) Gender Differences in the Effects of Prenatal Stress on Brain Development and Behaviour. Neurochem Res 32:1730-1740

37. Berger-Sweeney J, Hohmann CF (1997) Behavioral consequences of abnormal cortical development: insights into developmental disabilities. Behav Brain Res 86:121-142

38. Staller J, Faraone SV (2006) Attention-deficit hyperactivity disorder in girls: epidemiology and management. CNS Drugs 20:107-123 
Table 1. Baseline characteristics of the study population ${ }^{\text {a }}$

\begin{tabular}{|c|c|c|c|}
\hline Variables & $\begin{array}{l}\text { Exposed } \\
\text { cohort }\end{array}$ & $\begin{array}{l}\text { Unexposed } \\
\text { cohort }\end{array}$ & P value \\
\hline Gender & & & 0.92 \\
\hline Boys & $14929(51)$ & $506666(51)$ & \\
\hline Girls & $14165(49)$ & $480150(49)$ & \\
\hline Birth year & & & $<0.05$ \\
\hline 1987-1994 & $10356(36)$ & 455375 (46) & \\
\hline $1995-1998$ & $8944(31)$ & $274539(28)$ & \\
\hline $1999-2003$ & $9794(34)$ & $256904(26)$ & \\
\hline Apgar score at 5 minutes & & & 0.90 \\
\hline $0-7$ & $393(1)$ & $12844(1)$ & \\
\hline $8-9$ & $1623(6)$ & $52357(5)$ & \\
\hline 10 & $26193(90)$ & $844976(86)$ & \\
\hline Unknown & $885(3)$ & $76639(8)$ & \\
\hline Parity & & & 0.89 \\
\hline 1 & $11222(39)$ & $408279(41)$ & \\
\hline 2 & $11012(38)$ & $341933(35)$ & \\
\hline$>2$ & $6089(21)$ & $164660(17)$ & \\
\hline Unknown & $721(2)$ & 71939 (7) & \\
\hline Gestational age & & & $<0.05$ \\
\hline$<37$ weeks & $1798(6)$ & $50659(5)$ & \\
\hline$>=37$ weeks & 26575 (91) & $864217(88)$ & \\
\hline
\end{tabular}




\begin{tabular}{|c|c|c|c|}
\hline Unknown & $721(2)$ & $71939(7)$ & \\
\hline $\mathbf{S G A}^{\mathrm{b}}$ & & & 0.02 \\
\hline Yes & $3089(11)$ & $103827(11)$ & \\
\hline No & $25284(87)$ & $811050(82)$ & \\
\hline Unknown & $721(2)$ & $71939(7)$ & \\
\hline Maternal age & & & 0.60 \\
\hline $13-26$ & $4758(16)$ & $176971(18)$ & \\
\hline $27-30$ & $15956(55)$ & $518406(53)$ & \\
\hline$>30$ & $8380(29)$ & $288515(29)$ & \\
\hline Unknown & 0 & $2924(>1)$ & \\
\hline Maternal smoking at & & & $<0.05$ \\
\hline \multicolumn{4}{|l|}{ pregnancy } \\
\hline Yes & $6196(21)$ & $172964(18)$ & \\
\hline No & $16148(56)$ & $485052(49)$ & \\
\hline Unknown & $6750(23)$ & $328800(33)$ & \\
\hline Maternal history of & & & $<0.05$ \\
\hline \multicolumn{4}{|l|}{ psychiatric illness } \\
\hline Yes & $1092(4)$ & 31469 (3) & \\
\hline No & $28002(96)$ & $955347(97)$ & \\
\hline Maternal education & & & $<0.05$ \\
\hline Primary & $11172(38)$ & $374415(38)$ & \\
\hline Secondary & $10114(35)$ & $319230(32)$ & \\
\hline High & $7597(26)$ & $245383(25)$ & \\
\hline
\end{tabular}




Unknown $211(1) \quad 47789(5)$

\section{Maternal income}

0.19

$\begin{array}{lll}1^{\text {st }} \text { quartile } & 9388(32) & 311828(32) \\ 2^{\text {nd }} \text { quartile } & 12105(42) & 376823(38) \\ 3^{\text {rd }} \text { quartile } & 5563(19) & 187974(19) \\ 4^{\text {th }} \text { quartile } & 1827(6) & 62403(6) \\ \text { Unknown } & 211(1) & 47789(5)\end{array}$

\section{Maternal marital status}

$<0.05$

$\begin{array}{lll}\text { Yes } & 11137(38) & 338946(34) \\ \text { No } & 17746(61) & 600081(61) \\ \text { Unknown } & 211(1) & 47789(5)\end{array}$

\section{Maternal residence}

Copenhagen

$6709(23)$

$242431(26)$

Cities $^{c}$

$3367(12)$

$112340(11)$

Other

$18807(65)$

$584256(59)$

Unknown

$211(1)$

$47789(5)$

\footnotetext{
${ }^{\mathrm{a}}$ Value is $\mathrm{n}(\%)$

${ }^{\mathrm{b}}$ Small for gestational age.

${ }^{\mathrm{c}}$ Cities with over 100000 inhabitants.
} 
Table 2 ADHD cases defined by hospitalisation or medication

Medication Total cases

\section{Hospitalisation}

\begin{tabular}{lllll}
\hline Boys and Girls & & No & Yes & \\
& No & 1005632 & 4004 & \\
& Yes & 2637 & 3637 & 10278
\end{tabular}

Boys

$\begin{array}{llll}\text { No } & 513148 & 3249 & \\ \text { Yes } & 2152 & 3076 & 8477\end{array}$

\section{Girls}

\begin{tabular}{llll} 
No & 492484 & 785 & \\
Yes & 485 & 561 & 1831 \\
\hline
\end{tabular}


Table 3. The hazard ratio (HR) for ADHD in the offspring according to maternal bereavement during prenatal period, by gender, type of relatives, and cause of death

$\begin{array}{lll}\text { Cases in the } & \text { Crude } & \text { Adjusted HR } \\ \text { exposed } / & \text { hazard ratio } & (95 \% \mathrm{CI})^{\mathrm{a}} \\ \text { cases in the } & (\mathrm{HR}) & \\ \text { unexposed } & & \end{array}$

Boys \& girls

$\begin{array}{llll}\text { Death of a child or partner } & 55 / 9982 & 1.19 & 1.18(0.91-1.54) \\ \text { Unexpected death } & 21 / 9982 & 1.67 & 1.62(1.04-2.46)^{*} \\ \text { Other death } & 34 / 9982 & 1.03 & 1.01(0.72-1.41) \\ \text { Death of other relatives } & 245 / 7987 & 1.13 & 0.98(0.86-1.13) \\ \text { Unexpected death } & 76 / 7987 & 1.42 & 1.07(0.85-1.33) \\ \text { Other death } & 169 / 7987 & 1.04 & 0.95(0.82-1.11)\end{array}$

Boys

$\begin{array}{llll}\text { Death of a child or partner } & 51 / 8201 & 1.39 & 1.37(1.03-1.79)^{*} \\ \text { Unexpected death } & 18 / 8201 & 1.77 & 1.72(1.09-2.73)^{*} \\ \text { Other death } & 33 / 8201 & 1.24 & 1.21(0.86-1.71) \\ \text { Death of other relatives } & 199 / 6575 & 1.11 & 0.96(0.83-1.10) \\ \quad \text { Unexpected death } & 62 / 6575 & 1.38 & 1.06(0.83-1.36) \\ \text { Other death } & 137 / 6575 & 1.00 & 0.92(0.78-1.09)\end{array}$

\section{Girls}

\begin{tabular}{cccc} 
Death of a child or partner & $4 / 1781$ & 0.47 & $0.45(0.17-1.20)$ \\
Unexpected death & $3 / 1781$ & 1.31 & $1.17(0.38-3.64)$ \\
\hline
\end{tabular}




\begin{tabular}{lccc}
\hline Other death & $1 / 1781$ & 0.16 & $0.16(0.02-1.13)$ \\
Death of other relatives & $46 / 1412$ & 1.23 & $1.06(0.79-1.42)$ \\
Unexpected death & $14 / 1412$ & 1.52 & $1.12(0.66-1.42)$ \\
Other death & $32 / 1412$ & 1.13 & $1.04(0.73-1.47)$ \\
\hline
\end{tabular}

${ }^{\mathrm{a}}$ Hazard ratio (HR) adjusted for birth year, gestational age, Apgar score at 5 minutes, parity, SGA, maternal variables (smoking during pregnancy, age, psychiatric history, income, school education, residence, cohabitation).

$* \mathrm{P}<0.05$ 
Table 4. The hazard ratio (HR) for ADHD diagnosis or medication in male offspring following maternal bereavement during prenatal period, by type of deceased relatives

$\begin{array}{lll}\text { Cases in the } & \text { Crude } & \text { Adjusted HR } \\ \text { exposed / cases } & \text { hazard ratio } & (95 \% \mathrm{CI})^{\mathrm{a}} \\ \text { in the unexposed } & (\mathrm{HR}) & \end{array}$

Hospitalization

Death of a child or partner $\quad 46 / 5073$

1.41

$1.37(0.97-1.95)$

Unexpected death

$10 / 5073$

1.61

$1.53(0.82-2.84)$

Other death

22/5073

1.34

$1.31(0.86-2.00)$

Death of other relatives

$125 / 4085$

1.11

$0.96(0.81-1.15)$

Unexpected death

$36 / 4085$

1.24

$0.95(0.69-1.32)$

Other death

$89 / 4085$

1.06

$0.96(0.78-1.19)$

\section{Medication}

$\begin{array}{llll}\text { Death of a child or partner } & 38 / 6109 & 1.37 & 1.35(0.98-1.86) \\ \text { Unexpected death } & 12 / 6109 & 1.77 & 1.53(0.87-1.88) \\ \text { Other death } & 26 / 6109 & 1.30 & 1.28(0.87-2.67) \\ \text { Death of other relatives } & 152 / 4900 & 1.16 & 1.00(0.85-1.17) \\ \text { Unexpected death } & 45 / 4900 & 1.43 & 1.06(0.79-1.41) \\ \text { Other death } & 107 / 4900 & 1.08 & 0.97(0.80-1.18) \\ \text { Hazard ratio (HR) adjusted for birth year, gestational age, Apgar score at } 5 \text { minutes, } \\ \text { parity, SGA, maternal variables (smoking during pregnancy, age, psychiatric history, } \\ \text { ncome, school education, residence, cohabitation). }\end{array}$


Table 5. The hazard ratio (HR) for ADHD in male offspring following maternal bereavement during prenatal period, by type of relatives, timing of death

\begin{tabular}{|c|c|c|c|}
\hline & $\begin{array}{l}\text { Cases in } \\
\text { the exposed } \\
\text { / cases in } \\
\text { the } \\
\text { unexposed }\end{array}$ & $\begin{array}{l}\text { Crude } \\
\text { hazard } \\
\text { ratio } \\
\text { (HR) }\end{array}$ & $\begin{array}{l}\text { Adjusted HR } \\
(95 \% \mathrm{CI})^{\mathrm{a}}\end{array}$ \\
\hline \multicolumn{4}{|l|}{ Death of a child or spouse } \\
\hline $\begin{array}{l}\text { During } 12 \text { to } 7 \text { months before } \\
\text { conception }\end{array}$ & $14 / 8201$ & 0.98 & $0.95(0.57-1.61)$ \\
\hline During 6 - 0 months before conception & $26 / 8201$ & 1.44 & $1.47(1.00-2.16)^{*}$ \\
\hline Death during pregnancy & $11 / 8201$ & 2.43 & $2.10(1.16-3.80)^{*}$ \\
\hline First trimester & $2 / 8201$ & 1.39 & $1.23(0.31-4.94)$ \\
\hline Second trimester & $4 / 8201$ & 2.66 & $2.07(0.78-5.51)$ \\
\hline Third trimester & $5 / 8201$ & 3.04 & $2.98(1.24-7.16)^{*}$ \\
\hline \multicolumn{4}{|l|}{ Death of other relatives } \\
\hline $\begin{array}{l}\text { During } 12 \text { to } 7 \text { months before } \\
\text { conception }\end{array}$ & $53 / 6575$ & 0.99 & $0.84(0.64-1.10)$ \\
\hline During 6 - 0 months before conception & $67 / 6575$ & 1.35 & $1.18(0.94-1.51)$ \\
\hline Death during pregnancy & $79 / 6575$ & 1.03 & $0.90(0.72-1.13)$ \\
\hline First trimester & $23 / 6575$ & 1.01 & $0.89(0.59-1.34)$ \\
\hline
\end{tabular}




\begin{tabular}{lccc}
\hline Second trimester & $30 / 6575$ & 1.09 & $0.96(0.67-1.38)$ \\
Third trimester & $26 / 6575$ & 0.98 & $0.84(0.57-1.24)$ \\
\hline
\end{tabular}

${ }^{\mathrm{a}}$ Hazard ratio (HR) adjusted for birth year, gestational age, Apgar score at 5 minutes,

SGA, parity, maternal variables (smoking during pregnancy, age, psychiatric history, income, school education, residence, cohabitation).

$* \mathrm{P}<0.05$ 